\title{
Assessing the Effects of Indirect Left Turn on a Signalized Intersection Performance: A Case Study for the Tehran Metropolitan Area
}

\author{
Maxim A. Dulebenets ${ }^{1 *}$, Amir M. Rahimi², Arash Mazaheri² \\ ${ }^{1}$ Department of Civil \& Environmental Engineering, Florida A\&M University-Florida State University, Tallahassee, FL, USA \\ ${ }^{2}$ Department of Civil Engineering, University of Zanjan, Zanjan, Iran \\ Email: mdulebenets@eng.famu.fsu.edu
}

How to cite this paper: Dulebenets, M.A., Rahimi, A.M. and Mazaheri, A. (2017) Assessing the Effects of Indirect Left Turn on a Signalized Intersection Performance: A Case Study for the Tehran Metropolitan Area. Open Journal of Applied Sciences, 7, 617-634.

https://doi.org/10.4236/ojapps.2017.711045

Received: September 28, 2017

Accepted: November 5, 2017

Published: November 8, 2017

Copyright $\odot 2017$ by authors and Scientific Research Publishing Inc. This work is licensed under the Creative Commons Attribution International License (CC BY 4.0).

http://creativecommons.org/licenses/by/4.0/

(c) $\underset{\mathrm{EY}}{\mathrm{C}}$ Open Access

\begin{abstract}
Many signalized intersections are characterized with frequent left-turn moves. Vehicles waiting for a protected left turn may form long queues, which will increase the intersection delay and negatively impact the network performance. Researchers and practitioners across various countries underline that access management leads to a smoother traffic flow. One way of access management at intersections is to eliminate the direct left-turn maneuver. This study aims to evaluate how the traffic conditions will be affected from replacing the direct left turn with the right-turn U-turn maneuver at intersections. In case of the right-turn U-turn maneuver, a vehicle turns right instead of making the left turn and travels either to the median opening or to the next intersection to make a U-turn. Two simulation models are built using the Synchro Studio and Aimsun simulation software packages based on the data, collected from one of the busiest intersections in Tehran (Iran), to quantify the effects of replacing the direct left turn with the right-turn U-turn maneuver on the intersection and network performance. Results of a comprehensive simulation analysis indicate that the proposed access management treatment not only significantly reduces the total vehicle queue length and the total delay at the considered intersection, but also decreases the total network delay and the total travel time. Furthermore, elimination of the direct left turn increases the number of vehicles entering the network.
\end{abstract}

\section{Keywords}

Transportation Engineering, Signalized Intersection, Indirect Left Turn, Access Management, Traffic Simulation, Synchro, Aimsun 


\section{Introduction}

An increasing demand for passenger and freight transport over the last decades caused a significant increase in the roadway congestion [1]-[12]. London (United Kingdom), Stuttgart (Germany), and Antwerp (Belgium) were named as the most congested cities in Europe with the total delays of 101 hours, 73 hours, and 71 hours per commuter traveler respectively in 2015 [13]. The total delay in London increased by 5.2 hours between 2014 and 2015. A fast economic growth and record population levels were found to be the primary reasons of increasing traffic congestion [13]. Similar tendencies were reported in the United States (U.S.). According to the statistical data, provided by the INRIX consulting company, nine out of twenty the most congested cities in the word are located in the U.S., including Los Angeles, New York, San Francisco, Atlanta, Miami, Washington (D.C.), Dallas, Boston, and Chicago [14]. A commuter in the city of Los Angeles on average spent 104.1 hours in traffic jams in 2016. As a result of increasing traffic congestion, approximately 9 million jobs were lost in the U.S. over the last years [15]. Furthermore, the traffic congestion caused American drivers to waste more than 3 billion gallons of fuel [15]. The latter also increased the amount of emissions, produced by vehicles, and negatively affected the environment.

Cambridge Systematics [16] listed the following major reasons, causing the traffic congestion in the U.S.: 1) physical bottlenecks due to lack of the roadway capacity; 2) traffic incidents; 3) work zones; 4) weather; 5) disruption of traffic flow by traffic control devices; and 6) traffic demand fluctuations. Some of the aforementioned reasons cause traffic congestion in other countries as well. Generally, the existing congestion mitigation strategies can be divided into three groups [16]. The first group aims to add more capacity by increasing the number and size of the existing roadways. The second group of congestion mitigation strategies aims to manage the existing capacity more efficiently, while the last group encourages the travel and land use patterns that use the roadway system in less congestion producing ways. Nowadays, many transportation authorities rely on access management, which falls under the second group of congestion mitigation strategies.

A large variety of access management techniques have been implemented in the past to improve performance of the roadway segments around the world. The National Cooperative Highway Research Program (NCHRP) report "Impacts of Access Management Techniques" highlights that there are more than 100 access management techniques, which can be used to achieve different goals [17]. Generally, application of access management techniques allows preserving the existing roadway capacity and improving safety by reducing the number of crashes. The access management techniques may be classified into two groups [17]: a) policy-management techniques (access codes/spacing, zoning/subdivision regulations, purchase of access rights, and establishments of setbacks from interchanges and intersections); and b) design-operations techniques (inter- 
changes, frontage roads, median-left turns, right turns, access/driveway location, traffic control, and access/driveway design). The policy-management techniques are critical in access management and provide a foundation for the design-operations techniques. The design-operations techniques also play a very important role as they directly affect the traffic flow patterns on the roadway segments.

One of the most efficient design-operations techniques, which can serve as an alternative to the direct left-turn (DLT) maneuvers, is application of the right-turn followed by U-turn (RTUT) maneuver. In case of the RTUT maneuver, the vehicle, intending to make a left turn, turns right and travels either to the median opening or to the next intersection to make a U-turn. Replacing of the DLT maneuver with the RTUT maneuver allows reducing the number of conflict points and improves safety of travelers. Moreover, application of the RTUT maneuver generally increases the intersection capacity due to decrease in the total stop delay. However, depending on the location of median opening or intersection for the U-turn, the RTUT maneuver may increase the total travel distance and the total travel time of vehicles as compared to the DLT maneuver [18].

Considering a growing demand for passenger and freight transport and increasing congestion levels, this study aims to quantify the effects of replacing the DLT maneuver with the RTUT maneuver on the intersection and network performance. A case study is conducted for the Abu Saeed-Khalije Fars intersection, which is considered as one of the most congested areas in the Tehran metropolitan area (Iran). Two simulation models are built using the Synchro Studio and Aimsun software packages to estimate both intersection and network performance indicators before and after access management. Application of the developed simulation models will assist with estimating the major intersection and network performance indicators and quantifying potential advantages from replacing the DLT maneuver with the RTUT maneuver. The remainder of the manuscript is organized in the following manner. The next section presents a review of the literature on access management with focus on implementation of the RTUT maneuver. The third section describes in details the DLT and RTUT maneuvers and provides estimations of the total travel time and the total delay for both maneuvers. The fourth section describes the study area, data collection, and research methodology adopted. The fifth section presents the simulation experiments that were conducted in this study, while the last section summarizes findings and provides future research extensions.

\section{Literature Review}

As mentioned in the introduction section of the paper, a large variety of access management techniques have been widely used in the past to preserve the roadway capacity and reduce the number of crashes [17]. The RTUT maneuver is generally applied to replace the DLT maneuver. Despite the fact that the right-turn maneuver is typically used more frequently at intersections, the DLT 
maneuver is considered as one of the major factors causing traffic congestion at intersections and safety concerns [19]. Many transportation authorities introduced a number of policies in order to restrict utilization of the DLT maneuvers. For example, the State of Florida (U.S.) adopted a Multilane Facilities Median Policy in 1993, according to which all new or reconstructed multilane highways with a design speed over $40 \mathrm{mph}$ were required to have a restrictive median [20]. A closing of median opening at the major arterial roads required the vehicles, initially aiming to make a left turn, to travel to the downstream median opening or signalized intersection to make a U-turn. Considering an increasing implementation of the indirect left-turn maneuvers, this section of the paper aims to review the published to date studies, discussing the roadway operational performance and safety effects from replacing the DLT maneuvers with the indirect left-turn maneuvers. The collected studies were categorized into two groups based on the considered effects from applying the indirect left-turn maneuver: 1) roadway operational performance effects; and 2) safety effects.

\subsection{Roadway Operational Performance Effects}

Maki [21] performed a comparative analysis of the indirect left-turn and DLT maneuvers on the Michigan roadways with 4 and 6 lanes. It was found that the roadway capacity increased by $20 \%$ - 50\% from implementing the indirect left-turn maneuver. Gluck et al. [17] focused on the analysis of various access management techniques. The report highlighted that application of the RTUT maneuver could increase the total travel time by approximately $1 \mathrm{~min}$ as compared to the DLT maneuver, assuming a distance of $320 \mathrm{ft}$ between the intersection and the median opening. Lu et al. [22] conducted a study to evaluate the effects of access management on the roadway operational performance of ten sites in Florida. Two alternative treatments were considered: 1) the DLT maneuver; and 2) the RTUT maneuver at the median opening. The analysis was performed using the CORSIM simulation software. Computational experiments indicated that replacing the DLT maneuver with the RTUT maneuver significantly reduced the total travel time and the total delay. The total delay was reduced by $15 \%$ and $22 \%$ during peak and off-peak periods respectively.

Fan [20] assessed the effects of replacing the DLT maneuver with the RTUT maneuver in the Tampa Bay metropolitan area (Florida, U.S.). A total of eight sites were selected and more than 300 hours of the field data were recorded (including travel time, delay, headway, traffic volume, signal timing, etc.). A number of statistical models were developed to evaluate the total vehicle travel time and delay. It was found that application of the RTUT maneuver at the signalized intersections increased the total vehicle travel time and delay as compared to the DLT maneuver. Liu et al. [23] compared three driveway left-turn alternatives, including the following: a) the DLT maneuver; b) the RTUT maneuver at the median opening; and c) the RTUT maneuver at the signalized intersection. The analysis was performed using the data collected from 40 roadway segments in 
Central Florida. Results indicated that the indirect left-turn maneuver did not result in increasing vehicle travel time and delay if the median opening was provided in advance of the downstream signalized intersection.

El Esawey and Sayed [24] compared the four-leg conventional median U-turn intersection to the alternative median U-turn intersection. While conventional median U-turn intersection fully or partially prohibited the left-turn moves, the alternative median $\mathrm{U}$-turn intersection required the through and left-turn traffic, coming from the minor street, to re-route through RTUT at a median opening located on the major street. The analysis was conducted using the VISSIM simulation software. The traffic signal timing was optimized using the Synchro software. Numerical experiments were performed using the transportation network data, collected from the City of Cairo (Egypt), and results showed that the capacity of the alternative median U-turn intersection was $27 \%$ lower as compared to the conventional four-leg intersection. However, despite a poor performance, the alternative median U-turn intersection was still adopted by the city officials to address the problem of drivers' non-compliance with the traffic regulations.

Yang et al. [25] assessed the effects of left-turn waiting areas on capacity and level of service of signalized intersections. The traffic data (including saturation headway, start-up lost time, and clearance time) were collected from 22 approaches of 8 signalized intersections in the Nanjing area (China). The capacity and delay models were developed based on the Highway Capacity Manual methodology. Results indicated that an increasing left-turn waiting area increased the capacity of left-turn lanes at intersections. Furthermore, presence of the left-turn waiting area did not substantially affect the saturation headways and the clearance lost time of passenger vehicles that were making a left turn. However, an increase in the storage capacity of the left-turn waiting areas caused an increasing start-up lost time. Zhao et al. [26] proposed a lane-based optimization model for the integrated design of median U-turn intersection types, distances between the median crossovers and the main intersection, lane markings, and signal timings. The objective aimed to maximize the total intersection capacity. An iterative optimization algorithm was developed to solve the problem. Numerical experiments demonstrated that the proposed methodology could serve as an efficient tool in selection of the U-turn types and design of intersections with median U-turns.

Park et al. [27] performed a study on installation of U-turn lanes at signalized intersections using the traffic data, collected from the Incheon metropolitan area (South Korea). The authors analytically estimated the recommended U-turn lane length and the minimum separation distance from the front of intersection to the starting point of the U-turn lane. It was found that for the considered study area the recommended U-turn lane length comprised $32 \mathrm{~m}$. The minimum separation distances of $72 \mathrm{~m}, 40 \mathrm{~m}$, and $24 \mathrm{~m}$ were estimated for signalized intersections with 1 left-turn lane, 2 left-turn lanes, and 3 left-turn lanes respectively. It was highlighted that the research findings could improve efficiency and safety of the 
left-turn maneuvers. Taha and Abdelfatah [28] evaluated the advantages of replacing the DLT maneuver with the RTUT or U-turn followed by right-turn (UTRT) maneuvers. The analysis was performed using the Synchro and VISSIM software packages. Numerical experiments indicated that application of the RTUT or UTRT maneuvers reduced the total intersection delay. However, the unconventional left-turn control types (i.e., RTUT and UTRT) were found to have higher vehicle kilometers traveled as compared to the conventional DLT maneuver. Zhao et al. [29] presented a theoretical model for computing the lane group capacity at signalized intersections, taking into account the effects of access points. Two access point locations were considered in the study: (a) upstream of the signalized intersection; and (b) downstream of the signalized intersection. A VISSIM simulation model was built to evaluate the proposed methodology. Computational experiments showed that an increasing distance between the intersection and the access point could increase the intersection capacity.

\subsection{Safety Effects}

Along with reduction in the total vehicle delay and increase in the roadway capacity, many studies underline that application of RTUT decreases the number of crashes and improves safety. Gluck et al. [17] highlighted that replacing the DLT maneuver with the RTUT maneuver could reduce the accident rate by $20 \%$ at unsignalized intersections and by $35 \%$ at signalized intersections. The latter estimates were derived based on the data collection from various intersections in the U.S. Carter et al. [30] conducted a study to determine the safety and operational effects of $U$-turns at signalized intersections. The analysis was performed using the data, collected from 78 signalized intersections in North Carolina (U.S.). It was found that 65 out of 78 intersections did not have any collisions involving the U-turns for 3 years. The number of U-turn collisions at the remaining intersections varied from 0.33 to 3.0 collisions per year.

$\mathrm{Lu}$ et al. [31] focused on assessment of the safety impacts associated with replacing the DLT maneuver with the RTUT maneuver. Nine types of traffic conflicts were analyzed using the data, collected from eight sites in the Tampa Bay metropolitan area (Florida, U.S.). Results demonstrated that the DLT movements on average generated 6.7 conflicts per hour, while the RTUT movements on average generated 2.4 conflicts per hour. Furthermore, the average number of conflicts per thousand vehicles comprised 40.6 and 26.2 for the DLT and RTUT maneuvers respectively. Due to higher number of conflicts, the DLT maneuver generally causes more crashes as compared to the RTUT maneuver. As underlined by Williams et al. [32] in the Access Management Manual, approximately $74 \%$ of crashes occur at the access points due to the DLT maneuver. Liu [33] evaluated the safety and operational performance impacts for the RTUT maneuvers in Florida. The field measurements were collected from 40 sites in the Tampa Bay metropolitan area. It was found that the separation distance between the driveway exits and the downstream U-turn locations substantially influenced 
the safety and operational performance for the vehicles, making the RTUT maneuvers. An increase in the separation distance generally reduced the crash rates at weaving segments, but increased the vehicle travel time. Liu et al. [34] also highlighted the importance of selecting the appropriate separation distance. It was mentioned that a $10 \%$ increase in the separation distance decreased the total number of crashes by $3.3 \%$.

Qi et al. [35] evaluated the operational and safety effects of directional median openings on the urban roadway performance. The analysis was conducted using a VISSIM simulation model based on the data, collected from a $3000 \mathrm{ft}$ corridor in Houston (Texas, U.S.). The study results suggested that full median openings should be avoided in the functional areas of signalized intersections. Furthermore, installation of directional median openings substantially reduced the number of crossing-traffic conflicts at the opening location, but increased the number of lane-changing conflicts in both downstream and upstream areas.

\subsection{Contribution}

The conducted literature review indicates that replacing the DLT maneuver with the RTUT maneuver generally allows increasing the intersection and network capacity, decreasing the total delay, and improving safety [22] [23] [30] [31]. Some studies highlighted that selection of an appropriate location for the median opening for the RTUT maneuver could also decrease the total travel time [22] [23]. However, certain studies reported an increase in the total travel time from application of the RTUT maneuver [17] [28]. A few studies found that replacing of the DLT maneuver by the RTUT maneuver could not only increase the total travel time, but also decrease the intersection capacity and increase the total delay [20] [24]. Therefore, a comprehensive analysis is required in order to determine if application of the RTUT maneuver would be advantageous for a given transportation network.

Taking into account increasing congestion levels in certain areas of Tehran (Iran), this study aims to quantify advantages from implementing the RTUT maneuver. Two simulation models are developed to estimate the intersection and network performance indicators before and after application of the RTUT maneuver for the Abu Saeed-Khalije Fars intersection, which is considered as one of the most congested areas in the Tehran metropolitan area. The proposed simulation models can further assist the decision makers and transportation planners with alleviating congestion and improving the overall transportation network performance.

\section{Description of the DLT and RTUT Maneuvers}

This section of the paper provides a detailed description of the DLT and RTUT maneuvers and presents a set of relationships that are generally used to estimate the average total travel time and total vehicle delay for both types of maneuvers.

In order to make the DLT maneuver, a vehicle should perform the following 
steps [20]:

- Step 1: Stop and wait on the minor road;

- Step 2: Select an appropriate headway, travel to the median, stop at the median, wait for an appropriate headway through the opposite traffic flow;

- Step 3: Accelerate to reach the operational speed on the major road.

Figure 1 provides an illustration of the steps necessary for a vehicle to perform the DLT maneuver. The average total travel time and total vehicle delay for the DLT maneuver can be determined by the following equations:

$$
\begin{gathered}
T T_{L}=T_{L 1}+T_{L 2}+T_{L 3} \\
T D_{L}=T_{L 1}+T_{L 2}
\end{gathered}
$$

where:

$T T_{L}$ - is the average total travel time required for the DLT maneuver (sec);

$T D_{L}$ - is the average total vehicle delay caused by the DLT maneuver (sec);

$T_{L 1}$ - is the average stop delay on the minor road (sec);

$T_{L 2}$ - is the average median stop delay (sec);

$T_{L 3}$ - is the average running time of a vehicle before it makes the DLT maneuver, excluding $T_{L 1}$ and $T_{L 2}$ (sec).

On the other hand, the RTUT maneuver includes the following steps [20]:

- Step 1: Stop at the minor road and make a right turn;

- Step 2: Perform accelerating and waving motion through the internal transmission lane and decelerate in the private left-turn lane downstream of the signalized intersection;

- Step 3: Wait for the green traffic light to perform a U-turn;

- Step 4: Accelerate to reach the operational speed on the major road.

Figure 2 provides an illustration of the steps necessary for a vehicle to perform the RTUT maneuver. The average total travel time and total vehicle delay for the RTUT maneuver can be estimated using the following equations:

$$
\begin{gathered}
T T_{R U}=T_{R U 1}+T_{R U 2}+T_{R U 3}+T_{R U 4} \\
T D_{R U}=T_{R U 1}+T_{R U 2}
\end{gathered}
$$

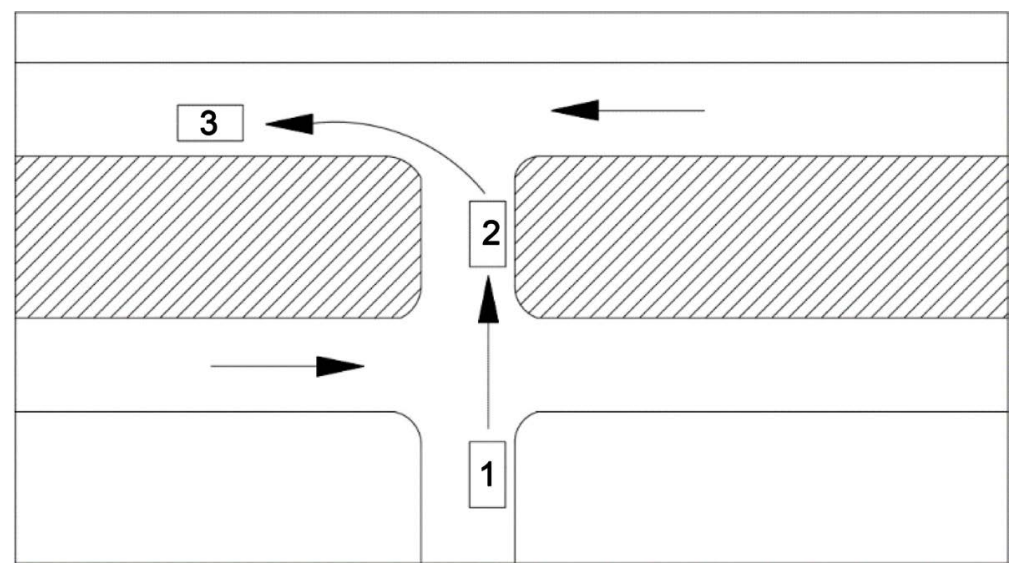

Figure 1. Illustration of the Steps Necessary for the DLT Maneuver. 


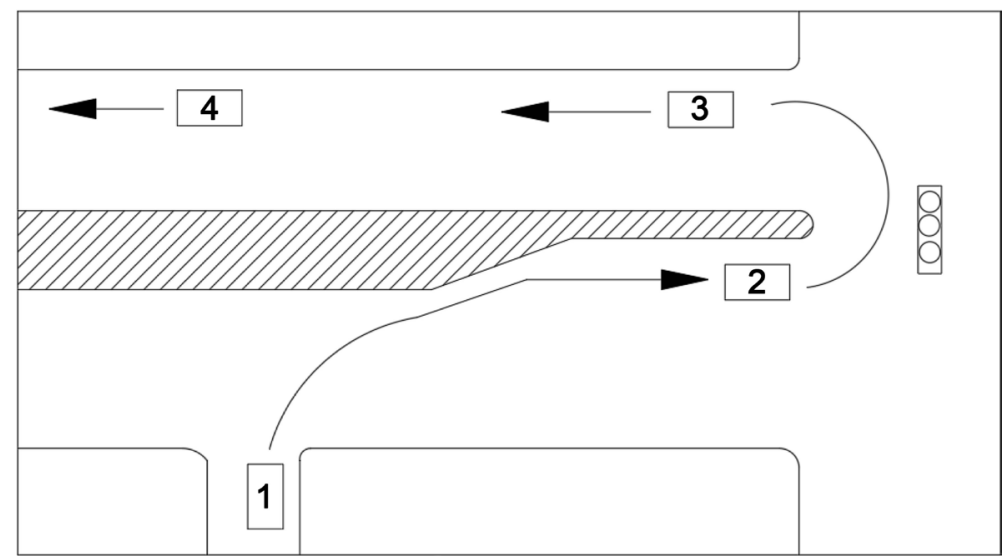

Figure 2. Illustration of the Steps Necessary for the RTUT Maneuver.

where:

$T T_{R U}$ - is the average total travel time required for the RTUT maneuver (sec);

$T D_{R U}$ - is the average total vehicle delay caused by the RTUT maneuver (sec);

$T_{R U 1}$ - is the average waiting delay on the minor road for a vehicle aiming to make a right turn $(\mathrm{sec})$;

$T_{R U 2}$ - is the average waiting delay on a left-turn private lane downstream of the intersection, where a vehicle aims to make a U-turn (sec);

$T_{R U 3}$ - is the average time between the moment when a vehicle leaves the minor road until that vehicle stops on the left-turn private lane downstream of the intersection, excluding $T_{R U 1}$ and $T_{R U 2}$ (sec);

$T_{R U 4}$ - is the average time required by the vehicles to cross the roadway at the posted speed limit (sec).

The time $T_{R U 4}$ can be calculated based on the weaving length from the minor road to the U-turn island $(I)$ and the vehicle travel speed $\left(V_{t}\right)$ using the following equation:

$$
T_{R U 4}=0.68 \cdot\left(l / V_{t}\right)
$$

The total travel time and the total vehicle delay are some of the primary indicators, which are generally used for assessing the intersection and network performance before and after application of the RTUT maneuver [20].

\section{Data Collection and Research Methodology}

This study focuses on evaluation of replacing the DLT maneuver with the RTUT maneuver at the Abu Saeed-Khalije Fars intersection, located in district 18 of the Tehran metropolitan area. The latter intersection is considered as one of the busiest intersections in the Tehran metropolitan area. Khalije Fars Boulevard and Abu Saeed Street have 3 and 2 lanes respectively, and width of each lane comprises $3.2-3.5 \mathrm{~m}$. The median widths of Khalije Fars Boulevard and Abu Saeed Street are $1 \mathrm{~m}$ and $2 \mathrm{~m}$ respectively. The traffic lights in the study area are pre-timed. The traffic signals have 2-phased cycles with a cycle length of 80 seconds at the status quo. The first phase (the north-south approach) has 47 
seconds of the green light and 30 seconds of the red light. The second phase (the east-west approach) has 27 seconds of the green light and 50 seconds of the red light. For each phase the yellow light comprises 3 seconds.

The traffic volumes were collected for 6 hours every day for 5 weekdays, 3 hours in the morning (08:00 am - 11:00 am) and 3 hours in the afternoon (16:30 $\mathrm{pm}-19: 30 \mathrm{pm})$. Note that the traffic data collection was performed under normal weather conditions. A total of 14 movement types were identified within the study area, and the estimated hourly traffic volumes (average values over 5 weekdays) for each movement type are illustrated in Figure 3. Throughout the data collection, the number of urban public transport buses and heavy vehicles were recorded as well (which are required in order to simulate the traffic flow), and results are presented in Table 1. Note that in this study the heavy vehicles

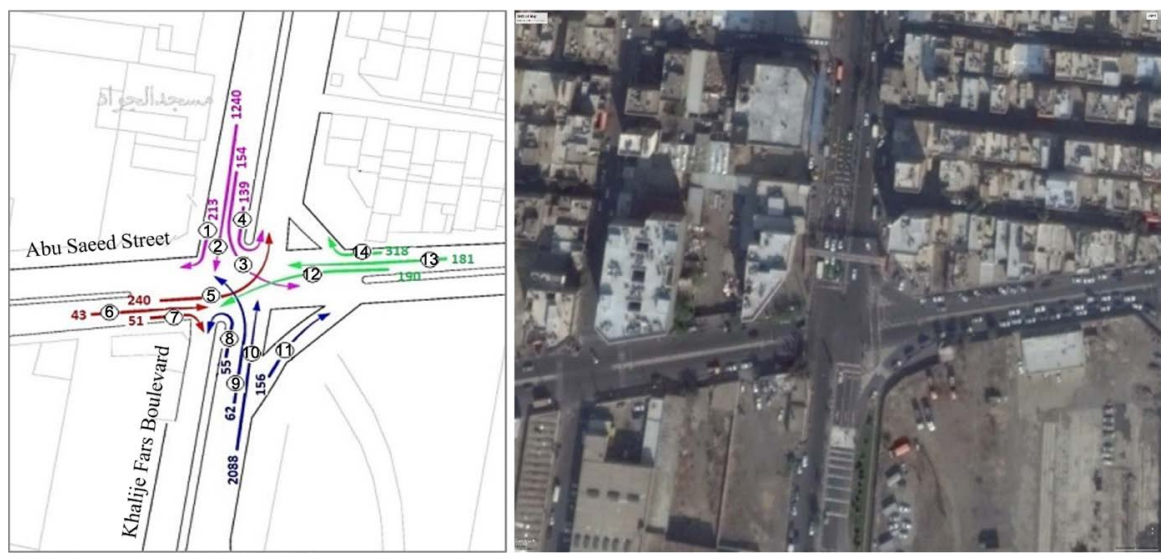

Figure 3. Estimated Traffic Flows Within the Study Area.

Table 1. Count Data for Buses and Heavy Vehicles.

\begin{tabular}{ccc}
\hline Movement Type & \#Buses, buses/hr & Heavy Vehicles, \% \\
\hline 1 & 5 & 7 \\
2 & 3 & 11 \\
3 & 7 & 4 \\
4 & 0 & 7 \\
5 & 0 & 9 \\
6 & 0 & 16 \\
7 & 0 & 11 \\
8 & 1 & 16 \\
9 & 10 & 14 \\
10 & 0 & 6 \\
11 & 1 & 11 \\
12 & 4 & 11 \\
13 & 4 & 7 \\
14 & 3 & \\
\hline & & \\
\hline
\end{tabular}


are classified as those vehicles, which have more than 4 wheels. After processing the collected data it was found that the morning and evening peak hours occur during 08:15 am - 9:15 am and 18:30 pm - 19:30 pm time periods respectively. The day peak hour volume was recorded to be 5040 vehicles. The peak hour factor (PHF) was calculated to be 0.89 . Note that the scope of this study does not include assessing monthly and seasonal variations in traffic flow, which will be one of the future research directions.

Two simulation models were built for the considered study area based on the collected data. The first simulation model was developed using the Synchro Studio 8.0 software package [36] to analyze performance indicators of the Abu Saeed-Khalije Fars intersection (e.g., intersection delay, intersection level of service, approach delay, queue length, etc.) under the existing conditions, where the vehicles were able to perform the DLT maneuver. The second simulation model was created using the Aimsun microsimulation software package [37] to analyze the network performance indicators within the study area (i.e., total network delay, traffic flow, traffic flow density, travel speed, total distance traveled, stop time, etc.) under the existing conditions.

After estimating the intersection and network performance indicators under the existing conditions the DLT maneuver was restricted, and the vehicles that intended to make a left turn were required to perform the RTUT maneuver at the median opening. Two median openings were placed in the study area: one median opening was created upstream (or before) and the second one was created downstream (or after) of the Abu Saeed-Khalije Fars intersection. The upstream median opening was designated for the U-turn movements of the vehicles, leaving the west approach of the Abu Saeed Street and heading north along the Khalije Fars Boulevard. The downstream median opening was designated for the U-turn movements of the vehicles, leaving the east approach of the Abu Saeed Street and heading south along the Khalije Fars Boulevard. The distance between the intersection and the median opening for the RTUT maneuver was set to $190 \mathrm{~m}$ (for both upstream and downstream median openings), which was found to be adequate based on the available literature for the urban signalized intersections in the Tehran metropolitan area [38]. Both simulation models were executed to calculate the updated intersection and network performance indicators and evaluate the access management effects from eliminating the DLT maneuver. Results of the conducted simulation experiments before and after access management are discussed in the following section.

\section{Simulation Experiments}

This section of the paper provides a detailed description of the simulation experiments that were performed to quantify the advantages from replacing the DLT maneuver with the RTUT maneuver on performance of the Abu Saeed-Khalije Fars intersection and surrounding network. The effects on intersection and network performance indicators are discussed in sections 5.1 and 5.2 respectively. 


\subsection{The Signalized Intersection Conditions before and after Access Management}

As indicated in section 4 of the paper, the Synchro Studio software was used to estimate performance indicators of the Abu Saeed-Khalije Fars intersection under the existing conditions (where the vehicles were allowed to make the DLT maneuver) and after access management (where the DLT maneuver was restricted and the vehicles were required to make the RTUT maneuver at the median opening either upstream or downstream of the intersection instead of making the DLT maneuver). Results of the conducted analysis are presented in Table 2, including the following performance indicators for each approach: 1) approach delay; 2) $50^{\text {th }}$ percentile queue length; 3 ) approach volume to capacity (V/C) ratio; 4) approach level of service (LOS); 5) intersection V/C ratio; 6) intersection delay; 7) intersection LOS; and 8) intersection capacity utilization (ICU). The traffic flows, emulated using the SimTraffic application of the Synchro Studio, before and after replacing the DLT maneuver are shown in Figure 4 for a simulated time of 7:30 am. We observe that application of access management significantly improved the traffic flow at the Abu Saeed-Khalije Fars intersection.

As a result of replacing the DLT maneuver with the RTUT maneuver the intersection V/C ratio and the total intersection delay decreased by $65.4 \%$ and $53.4 \%$ respectively, while the $50^{\text {th }}$ percentile queue length reduced on average by $47.8 \%$ over all approaches. The intersection capacity utilization decreased from 1.49 to 0.90 by eliminating the left-turn movements. Furthermore, results of the microsimulation analysis, conducted using the SimTraffic application, indicate that the number of vehicles entering the intersection increased from 2822 to 4852 vehicles per hour as a result of the proposed access management treatment.

\subsection{The Network Conditions before and after Access Management}

The Aimsun simulation software was used to develop a microsimulation model for the study area and estimate performance indicators of the surrounding net-

Table 2. Intersection Performance Indicators.

\begin{tabular}{|c|c|c|c|c|c|c|c|c|c|}
\hline \multirow{2}{*}{$\begin{array}{c}\text { Performance Indicator/ } \\
\text { Approach }\end{array}$} & \multicolumn{4}{|c|}{ Existing Condition } & \multicolumn{4}{|c|}{ After Access Management } & \multirow{2}{*}{ - Unit } \\
\hline & East & West & North & South & East & West & North & South & \\
\hline Approach Delay & 509.0 & 155.3 & 322.8 & 307.1 & 28.5 & 118.6 & 247.0 & 31.9 & $\mathrm{sec}$ \\
\hline $50^{\text {th }}$ Percentile Queue Length & 13.9 & 44.8 & 118 & 81.4 & 5.3 & 42.4 & 11.8 & 53.9 & $\mathrm{~m}$ \\
\hline Approach $\mathrm{V} / \mathrm{C}$ ratio & 1.04 & 1.72 & 1.65 & 1.06 & 0.27 & 1.25 & 1.50 & 0.97 & - \\
\hline Approach LOS & $\mathrm{F}$ & $\mathrm{F}$ & $\mathrm{F}$ & $\mathrm{F}$ & $\mathrm{C}$ & $\mathrm{F}$ & $\mathrm{F}$ & $\mathrm{C}$ & - \\
\hline Intersection $\mathrm{V} / \mathrm{C}$ ratio & \multicolumn{4}{|c|}{4.33} & \multicolumn{4}{|c|}{1.50} & \\
\hline Intersection Delay & \multicolumn{4}{|c|}{307.1} & \multicolumn{4}{|c|}{142.4} & $\mathrm{sec}$ \\
\hline Intersection LOS & \multicolumn{4}{|c|}{$\mathrm{F}$} & \multicolumn{4}{|c|}{$\mathrm{F}$} & - \\
\hline ICU & \multicolumn{4}{|c|}{1.49} & \multicolumn{4}{|c|}{0.90} & - \\
\hline
\end{tabular}



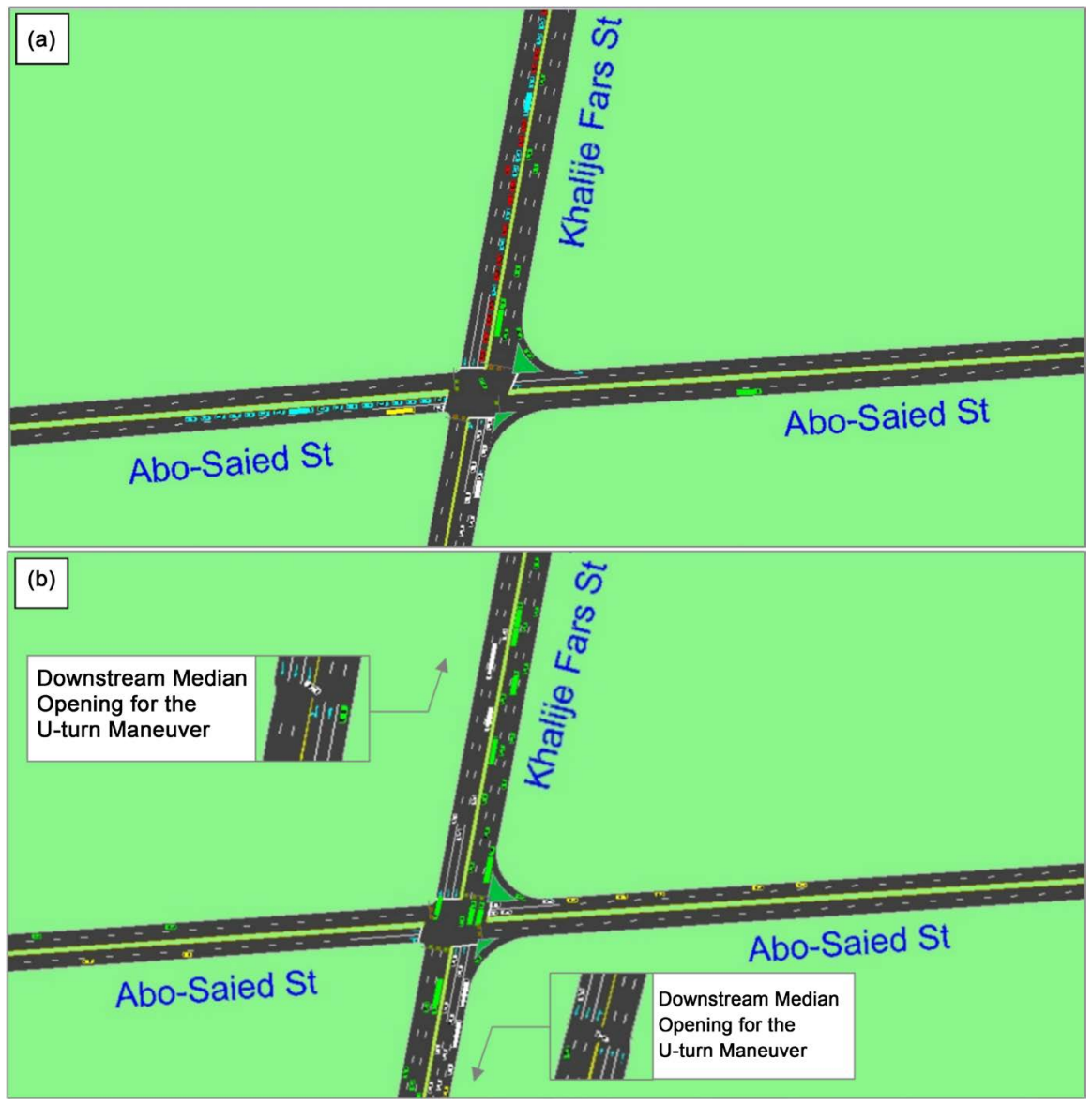

Figure 4. Simulated Study Area in SimTraffic: (A) Before Access Management, (B) After Access Management.

work. The warm-up time of the simulation model was set to $15 \mathrm{~min}$ based on preliminary simulation runs. The traffic flow was simulated 5 times. A total of 5 replications were found to be adequate, as the considered performance indicators did not fluctuate significantly from one replication to another. The duration of each simulation run was approximately $60 \mathrm{~min}$. The average values (over 5 replications) of the network performance indicators before and after access management are presented in Table 3, including the following: 1) delay time; 2) density; 3) flow; 4) fuel consumption; 5) harmonic travel speed; 6) travel speed; 7) stop time; 8) number of stops; 9) total distance traveled; 10) total travel time; and 11) travel time.

Note that the harmonic travel speed of vehicles was estimated as follows [37]:

$$
H S=\frac{n}{\sum_{i=1}^{n} \frac{1}{\frac{D_{i}}{T E X_{i}-T E N_{i}}}}
$$

where:

$$
\begin{aligned}
& H S \text { - harmonic speed of vehicles }(\mathrm{km} / \mathrm{hr}) \text {; } \\
& D_{i} \text { - total distance traveled by vehicle } i \text { in the network }(\mathrm{km}) \text {; }
\end{aligned}
$$


Table 3. Network Performance Indicators.

\begin{tabular}{cccc}
\hline Performance Indicator & Existing Condition & After Access Management & Unit \\
\hline Delay Time & 192.7 & 32.9 & $\mathrm{sec} / \mathrm{km}$ \\
Density & 36.2 & 17.7 & $\mathrm{veh} / \mathrm{km}$ \\
Flow & 4637.0 & 5068.0 & $\mathrm{veh} / \mathrm{hr}$ \\
Fuel Consumption & 502.5 & 322.6 & $\mathrm{liters}$ \\
Harmonic Travel Speed & 13.9 & 35.6 & $\mathrm{~km} / \mathrm{hr}$ \\
Travel Speed & 24.5 & 37.8 & $\mathrm{~km} / \mathrm{hr}$ \\
Stop Time & 169.0 & 22.0 & $\mathrm{sec} / \mathrm{km}$ \\
Number of Stops & 5.9 & 1.3 & \#stops $/ \mathrm{veh} / \mathrm{km}$ \\
Total Distance Traveled & 2884.0 & 3514.6 & $\mathrm{~km}$ \\
Total Travel Time & 205.2 & 100.7 & $\mathrm{hr}$ \\
Travel Time & 260.5 & 101.1 & $\mathrm{sec} / \mathrm{km}$ \\
\hline
\end{tabular}
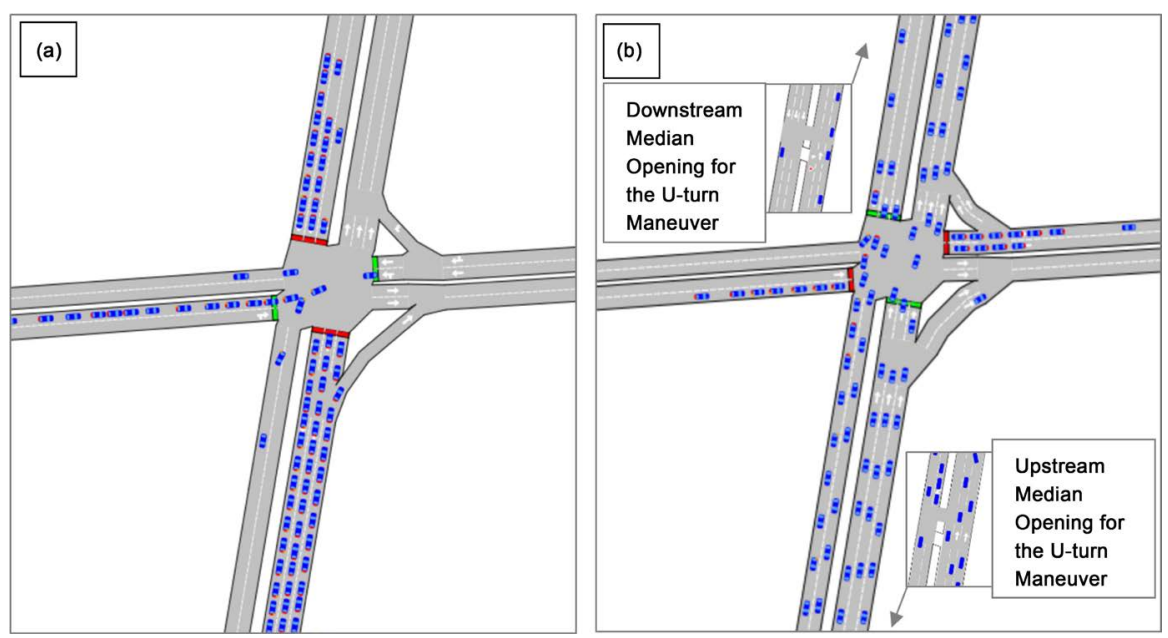

Figure 5. Simulated Study Area in Aimsun: (a) Before Access Management, (b) After Access Management.

$T E X_{i}$ - exit time of vehicle $i$ from the network (hr);

$T E N_{i}$ - entrance time of vehicle $i$ in the network (hr);

$n$ - total number of vehicles in the network (vehicles).

The traffic flows, simulated using the Aimsun simulation software, before and after replacing the DLT maneuver with the RTUT maneuver at the median opening are shown in Figure 5 for a simulated time of 7:30 am. Results of the simulation analysis demonstrate that access management significantly improved the network travel conditions in the area of Abu Saeed-Khalije Fars intersection. Specifically, the total delay and travel time decreased by $82.9 \%$ and $50.9 \%$ respectively. Elimination of the DLT maneuver increased the average travel speed of vehicles from $24.5 \mathrm{~km} / \mathrm{h}$ to $37.8 \mathrm{~km} / \mathrm{h}$, while the total stop time decreased from $169.0 \mathrm{sec} / \mathrm{km}$ to $22.0 \mathrm{sec} / \mathrm{km}$. Moreover, the proposed access management treatment reduced the total number of vehicle stops by $78.1 \%$. 
However, the total travel distance increased by $21.9 \%$ from application of the RTUT maneuver. The latter can be explained by the fact that the vehicles, intended to make a left turn, were required to travel to the median opening either downstream or upstream of the intersection to make a U-turn. Nevertheless, since the vehicles were able to travel at a higher speed, the total travel time after access management was found to be lower as compared to the existing condition, where the left-turn movements were allowed. The simulation experiments also indicate that access management allowed increasing the total traffic flow by $9.3 \%$, while the density of vehicles was reduced by $51.2 \%$. Furthermore, the total fuel consumption decreased by $35.8 \%$ after eliminating the DLT maneuver. Therefore, an efficient access management may not only improve the intersection and network performance indicators, but also alleviate negative environmental externalities (i.e., lower fuel consumption further leads to reduction of the emissions produced by vehicles).

\section{Conclusions and Future Research}

Nowadays transportation authorities have to implement efficient countermeasures in large metropolitan areas around the world to resolve the existing congestion issues and serve the growing demand for passenger and freight transport. Many access management techniques have been used in the past to increase the roadway capacity and improve safety. The right-turn followed by U-turn maneuver has been widely adopted to replace the direct left-turn maneuver, which generally causes long traffic queues and creates additional conflict points at intersections. This study conducted a comprehensive evaluation of the effects from application of the right-turn followed by U-turn maneuver on the intersection and network performance indicators. A case study was performed for the Abu Saeed-Khalije Fars intersection, one of the most congested areas in the Tehran metropolitan area (Iran). Two simulation models were developed using the Synchro Studio and Aimsun software packages to analyze the existing traffic conditions, where the direct left-turn maneuver was allowed, and the traffic conditions after access management, when the direct left-turn maneuver was replaced with the right-turn followed by U-turn maneuver either upstream or downstream of the intersection.

Results from simulation experiments indicated that elimination of the direct left-turn maneuver reduced the intersection volume to capacity ratio and the intersection delay by $65.4 \%$ and $53.4 \%$ respectively, while the $50^{\text {th }}$ percentile queue length decreased by $47.8 \%$ on average over all approaches. Furthermore, the proposed access management treatment decreased the intersection capacity utilization from 1.49 to 0.90 . The microsimulation analysis demonstrated that the total vehicle delay reduced by $82.9 \%$ from application of the right-turn followed by U-turn maneuver, and the average travel speed of vehicles increased from $24.5 \mathrm{~km} / \mathrm{h}$ to $37.8 \mathrm{~km} / \mathrm{h}$. However, the total travel distance increased by $21.9 \%$ after access management due to the fact that the vehicles, intending to make a 
left turn, were required to travel to the median opening to make a U-turn. Nevertheless, the total travel time decreased from restricting the direct left-turn movements due to an increase in the vehicle travel speed. Therefore, application of the right-turn followed by U-turn maneuver significantly improved performance indicators of the Abu Saeed-Khalije Fars intersection and surrounding network.

The future research may focus on the following extensions: 1) evaluate the access management effects for other intersections in the Tehran metropolitan area with high traffic flows; 2 ) collect the crash data for the study area and assess the safety effects from application of the right-turn followed by U-turn maneuver; 3) conduct the analysis for inclement weather conditions (e.g., rain, snow); 4) evaluate other alternative indirect left-turn maneuvers (e.g., through neighboring squares, jughandle intersections, left-turn maneuver followed by U-turn, and others).

\section{References}

[1] Flaskou, M., Dulebenets, M.A., Golias, M., Mishra, S. and Rock, B. (2015) Analysis of Freight Corridors Using GPS Data on Trucks. Transportation Research Record, 2478, 113-122. https://doi.org/10.3141/2478-13

[2] Dulebenets, M.A. (2015) Models and Solution Algorithms for Improving Operations in Marine Transportation. Dissertation, University of Memphis, Memphis, TN.

[3] Dulebenets, M.A. (2015) Bunker Consumption Optimization in Liner Shipping: A Metaheuristic Approach. International Journal on Recent and Innovation Trends in Computing and Communication, 3, 3766-3776.

[4] Dulebenets, M.A., Pujats, K., Deligiannis, N., Golias, M. and Mishra, S. (2017) Development of Tools for Processing Truck GPS Data and Analysis of Freight Transportation Facilities. Transportation Research Board, 96 ${ }^{\text {th }}$ Annual Meeting, 8-12 January 2017, Washington, D.C.

[5] Dulebenets, M.A., Ozguven, E.E., Moses, R. and Ulak, M.B. (2016) Intermodal Freight Network Design for Transport of Perishable Products. Open Journal of $O p$ timization, 5, 120-139. https://doi.org/10.4236/ojop.2016.54013

[6] Dulebenets, M.A. (2017) The Green Vessel Scheduling Problem with Transit Time Requirements in a Liner Shipping Route with Emission Control Areas. Alexandria Engineering Journal, 1-12. (In Press) https://doi.org/10.1016/j.aej.2016.11.008

[7] Dulebenets, M.A. (2016) The Vessel Scheduling Problem in a Liner Shipping Route with Heterogeneous Vessel Fleet. International Journal of Civil Engineering, 1-14. https://doi.org/10.1007/s40999-016-0060-Z

[8] Dulebenets, M.A. (2016) Advantages and Disadvantages from Enforcing Emission Restrictions within Emission Control Areas. Maritime Business Review, 1, 107-132. https://doi.org/10.1108/MABR-05-2016-0011

[9] Dulebenets, M.A. (2017) Application of Evolutionary Computation for Berth Scheduling at Marine Container Terminals: Parameter Tuning Versus Parameter Control. IEEE Transactions on Intelligent Transportation Systems, 1-13. https://doi.org/10.1109/TITS.2017.2688132

[10] Dulebenets, M.A., Moses, R., Ozguven, E.E. and Vanli, A. (2017) Minimizing Car- 
bon Dioxide Emissions Due to Container Handling at Marine Container Terminals via Hybrid Evolutionary Algorithms. IEEE Access, 5, 8131-8147. https://doi.org/10.1109/ACCESS.2017.2693030

[11] Dulebenets, M.A. and Ozguven, E.E. (2017) Vessel Scheduling in Liner Shipping: Modeling Transport of Perishable Assets. International Journal of Production Economics, 184, 141-156. https://doi.org/10.1016/j.ijpe.2016.11.011

[12] Dulebenets, M.A. (2016) A New Simulation Model for a Comprehensive Evaluation of Yard Truck Deployment Strategies at Marine Container Terminals. Open Science Journal, 1, 1-28.

[13] Business Insider (2017) These 10 Cities Have the Worst Traffic Jams in Europe. http://www.businessinsider.com/cities-with-the-worst-traffic-in-europe-2016-3

[14] Randall, D. (2017) Study Reveals Cities with Worst Traffic Congestion; U.S. WellRepresented.

http://nesn.com/2017/02/study-reveals-cities-with-worst-traffic-congestion-u-s-well -represented

[15] Davenport, R., Hoelscher, M. and Bak, J. (2017) Traffic Gridlock Sets New Records for Traveler Misery.

https://mobility.tamu.edu/ums/media-information/press-release

[16] Cambridge Systematics (2015) Traffic Congestion and Reliability: Trends and Advanced Strategies for Congestion Mitigation. Report Submitted to the Federal Highway Administration.

[17] Gluck, J.S., Levinson, H.S. and Stover, V.G. (1999) Impacts of Access Management Techniques. NCHRP Report 420, Transportation Research Board, Washington DC.

[18] Potts, I.B., Harwood, D.W., Torbic, D., Richard, K.R., Gluck, J.S., Levinson, H.S., Garvey, P.M. and Ghebrial, R. (2004) Safety of U-Turns at Unsignalized Median Openings. NCHRP Report 524, Transportation Research Board, Washington DC.

[19] Transportation Research Board (2010) Highway Capacity Manual. 5th Edition, National Academy of Sciences, Transportation Research Board, Washington DC.

[20] Fan, J. (2004) Operational Evaluation of Right Turns Followed by U-Turns at Signalized Intersections as an Alternative to Direct Left Turns. M.Sc. Thesis, University of South Florida, Tampa, FL.

[21] Maki, R.E. (1996) Directional Crossovers: Michigan's Preferred Left-Turn Strategy. $75^{\text {th }}$ Annual Meeting, Transportation Research Board, Washington DC.

[22] Lu, J., Dissanayake, S., Zhou, H., Yang, X. and Williams, K. (2001) Operational Evaluation of Right Turns Followed by U-Turns as an Alternative to Direct Left turns. Report Submitted to the Department of Transportation, University of South Florida.

[23] Liu, P., Lu, J.J., Pirinccioglu, F., Dissanayake, S. and Sokolow, G. (2007) Should Direct Left-Turns from Driveways Be Replaced by Right-Turns Followed by U-Turns? The Safety and Operational Comparison in Florida. $3^{\text {rd }}$ Urban Street Symposium: Uptown, Downtown, or Small Town: Designing Urban Streets That Work.

[24] El Esawey, M. and Sayed, T. (2011) Operational Performance Analysis of the Unconventional Median U-Turn Intersection Design. Canadian Journal of Civil Engineering, 38, 1249-1261. https://doi.org/10.1139/111-085

[25] Yang, Z., Liu, P., Tian, Z.Z. and Wang, W. (2013) Effects of Left-Turn Waiting Areas on Capacity and Level of Service of Signalized Intersections. Journal of Transportation Engineering, 139, 1076-1085.

https://doi.org/10.1061/(ASCE)TE.1943-5436.0000593 
[26] Zhao, J., Ma, W., Head, K. and Yang, X. (2014) Optimal Intersection Operation with Median U-Turn: Lane-Based Approach. Transportation Research Record, 2439, 71-82. https://doi.org/10.3141/2439-07

[27] Park, C., Yoon, B. and Kang, B. (2015) A Study on Installation of U-Turn Lane for Efficient Operation of Left Turn at Signalized Intersections. Journal of the Korean Society of Disaster Information, 11, 597-606. https://doi.org/10.15683/kosdi.2015.11.4.597

[28] Taha, M.A. and Abdelfatah, A.S. (2015) Impact of U-Turns as Alternatives to Direct left-Turns on the Operation of Signalized Intersections. Journal of Traffic and Logistics Engineering, 3, 12-17. https://doi.org/10.12720/jtle.3.1.12-17

[29] Zhao, J., Li, P. and Zhou, X. (2016) Capacity Estimation Model for Signalized Intersections under the Impact of Access Point. PloS One, 11, 1-16.

[30] Carter, D., Hummer, J., Foyle, R. and Phillips, S. (2005) Operational and Safety Effects of U-Turns at Signalized Intersections. Transportation Research Record, 1912, 11-18. https://doi.org/10.3141/1912-02

[31] Lu, J., Pirinccioglu, F. and Pernia, J. (2005) Safety Evaluation of Right Turns Followed by U-Turns at Signalized Intersections (6 or More Lanes) as an Alternative to Direct Left Turns-Conflict Analysis. Report Submitted to the Department of Transportation, University of South Florida.

[32] Williams, K.M., Stover, V.G., Dixon, K.K. and Demosthenes, P. (2014) Access Management Manual. National Academy of Sciences, Transportation Research Board, Washington DC.

[33] Liu, P. (2006) Evaluation of the Operational Effects of U-Turn Movement. Dissertation, University of South Florida, Tampa, FL.

[34] Liu, P., Lu, J.J. and Chen, H. (2008) Safety Effects of the Separation Distances between Driveway Exits and Downstream U-Turn Locations. Accident Analysis \& Prevention, 40, 760-767. https://doi.org/10.1016/j.aap.2007.09.011

[35] Qi, Y., Chen, X., Liu, G. and Wang, Y. (2014) Operational and Safety Impacts of Directional Median Opening on Urban Roadways: A Case Study in Houston, TX. $93^{\text {rd }}$ Annual Meeting, Transportation Research Board, Washington DC.

[36] Trafficware (2017) Synchro Studio 8.0-Planning \& Analysis Software. http://www.trafficware.com/synchro.html

[37] TSS-Transport Simulation Systems (2017) Aimsun Traffic Modelling Software. https://www.aimsun.com

[38] Mazaheri, A. and Rahimi, A.M. (2017) Determining a Suitable Position for U-Turns near Signal-Controlled Road Junctions. Proceedings of the Institution of Civil Engineers-Transport, 170, 267-275. https://doi.org/10.1680/jtran.15.00039 